\title{
7 The success view applied - Two rough sketches
}

As laid out in the introduction, I view this book, in part, as groundwork for the more systematic and informed exploration of various philosophical questions. To give you a flavor of how this may go, I want to close by sketching, very roughly, two applications of the success view to well-taken philosophical problems. One is the grandfather paradox, as it arises in connection with time travel. The other is the free will problem.

Why am I choosing those two problems and not any other? After all, several other philosophical problems seem to be just as well-suited to be re-considered in the light of the insights that the success view provides about abilities. We know that virtue epistemologists, such as Greco (2007) and Sosa (2015) analyze knowledge in terms of intellectual abilities. Certainly, it would be quite interesting to look at those abilities more closely against the background of the success view. The same goes for other theories which feature the notion of abilities at center stage, such as Millikan's theory of substance concepts (2000), Mayr's theory of action (2011), and various views of conceivability (Yablo 1993; Menzies 1998), to name but a few.

Why focus on time travel and free will? First, of course, because I have to make some choice. Secondly, I take it that time travel and freedom are particularly interesting to look at. The time travel topic is interesting because the standard solution to the grandfather paradox appeals to possibilism - a view I have discussed in great detail $(\rightarrow 3)$. It is therefore easily accessible against the background of this book and gives me the opportunity to take up a few threads that have been running through the previous chapters.

The reason for talking about free will in the outlook is that the debate about free will seems to me to be among the debates which have been the most strongly affected by a prevailing lack of understanding of abilities. That is because the debate has been dominated, in large part, by the idea that freedom requires agents to have the ability to act otherwise (Frankfurt 1969), but no one seems to know how to understand this requirement. Even worse, some of the most established players in the debate seem to be completely oblivious to the fact that there could be open questions about the understanding of that requirement.

Van Inwagen writes the following in response to the idea that compatibilists and incompatibilists about freedom and determinism may perhaps be talking past each other when fighting about whether or not the ability to act otherwise is or is nor compatible with determinism:

2 OpenAccess. (c) 2020 Jaster, published by De Gruyter. (cc) BY-NC-ND This work is licensed under the Creative Commons Attribution-NonCommercial-NoDerivatives 4.0 License. 
I want to make what seems to me to be an important point [... ]: compatibilists and incompatibilists mean the same thing by 'able.' And what do both compatibilists and incompatibilists mean by 'able'? Just this: what it means in English, what the word means. (van Inwagen $2008: 333$ )

To the reader of this book, it should be obvious that this stance towards the meaning of "able" is ignorant to an almost amusing degree. Ability statements, and this much is clear, are highly context sensitive. Hence, worries about whether compatibilists and incompatibilists may not in fact talk past each other obviously cannot be settled by pointing out that they both mean "what the word means" when they talk about abilities.

In my outlook on the applicability of the success view to the free will issue, I will try and push this very point. More specifically, I will use the insights of this book to come up with a contextualist view of freedom statements, which allows for a conciliatory perspective on the ongoing debate between compatibilists and incompatibilists about freedom and determinism. That is not to say that this is the only reasonable application of the success view to the free will problem, but it is a radical one and one worth exploring.

\subsection{A paradox about time travel revisited}

Let's start with the grandfather paradox. The paradox is this: if time travel were possible, then it would be possible for a situation to occur in which some agent can and cannot kill his own grandfather. Since that it impossible, time travel is impossible.

Here is Lewis's (1976: 149f.) exposition of the paradox. Suppose Tim travels back to the year 1921 to kill his grandfather. Back in the past, he buys a rifle, trains to shoot, tracks his grandfather down, and aims. Can Tim kill his grandfather? The answer seems to be: yes and no. On the one hand, he can; he clearly has what it takes, and the circumstances are just perfect. On the other hand, he cannot; if he could, he could do what is logically impossible. Tim obviously did not kill Grandfather in 1921, after all, because Grandfather lived on after that and, among other things, fathered Tim's father. If Tim killed him in 1921, it would therefore be true that he killed him in 1921 and did not kill him in 1921. Hence, it is logically impossible for Tim to kill Grandfather in 1921.

Is time travel incoherent, then? Not according to Lewis. If Lewis is right, then the grandfather paradox is merely apparent, because it equivocates on "can". How so? Here, we need to take a step back and take a look at Lewis's views about ability statements. 
As we know, Lewis is a possibilist. That is to say that, on Lewis's view, ability statements - and "can" statements quite generally - express restricted possibility claims: "S can $\phi$ ” is true, according to Lewis, if and only if S's $\phi$-ing is compossible with the relevant facts. In possible worlds terminology that is to say that

POSS. "S can $\phi$ " is true if and only if there is a relevant possible world in which S $\phi$ 's, where the relevant worlds are the worlds in which the relevant facts obtain.

We also know that possibilism is a contextualist view about ability statements. Which facts are relevant will vary across ascriber contexts. Recall Lewis's famous quote on that issue:

To say that something can happen means that its happening is compossible with certain facts. Which facts? That is determined (...) by context. An ape can’t speak a human language - say, Finnish - but I can. Facts about the anatomy and operation of the ape's larynx and nervous system are not compossible with his speaking Finnish. The corresponding facts about my larynx and nervous system are compossible with my speaking Finnish. But don't take me along to Helsinki as your interpreter: I can’t speak Finnish. My speaking Finnish is compossible with the facts considered so far, but not with further facts about my lack of training. What I can do, relative to one set of facts, I cannot do, relative to another, more inclusive, set. (ibid.:150)

Possibilism plays a crucial role in Lewis's solution to the grandfather paradox. That is because, on Lewis's view, the formulation of the paradox equivocates on "can" in that the set of facts relative to which Tim can kill his grandfather is different from the set of facts relative to which he cannot:

Tim's killing Grandfather that day in 1921 is compossible with a fairly rich set of facts: the facts about his rifle, his skill and training, the unobstructed line of fire, (...) and so on. (...) Relative to these facts, Tim can kill Grandfather. But his killing Grandfather is not compossible with another, more inclusive set of facts. There is the simple fact that Grandfather was not killed. (...) Relative to these facts, Tim cannot kill Grandfather. He can and he can't, but under different delineations of the relevant facts. You can reasonably choose the narrower delineation, and say that he can; or the wider delineation, and say that he can't. But choose. What you mustn't do is waver, say in the same breath that he both can and can't, and then claim that this contradiction proves that time travel is impossible. (ibid.: 151)

Here is Lewis's solution to the grandfather paradox in a nutshell:

SOLUTION. The formulation of the paradox equivocates on "can" and the paradox is therefore merely apparent. That is because Tim can kill Grandfather in one sense, but not in another, in that he can kill him, relative to one set of facts, but cannot kill him, relative to another. 
SOLUTION seems to be widely accepted throughout the literature on time travel. ${ }^{1}$ Yet, of course, it is ill-justified as it stands. The reason for that should be obvious. As I have shown at length in chapter 3, possibilism is false; ability statements are not plausibly understood as restricted possibility claims. Thus, SOLUTION relies on a false presupposition. And as a consequence, it stands on very shaky ground.

What I want to show in what follows, however, is that the same solution flows out of an ameliorated view of abilities - specifically: the success view of ability. Lewis's solution to the grandfather paradox is therefore on the right track, despite the fact that the view of abilities which underlies it is mistaken.

To see this, note that possibilism contains two elements: a restriction of the possible worlds to the ones that are relevant in a context, and the postulate that there be at least one among those worlds in which the agent ф's. As we know, there is something wrong with the latter of those elements. There being at least one relevant $\phi$-ing world is often not enough for an agent to have an ability, and it certainly does not provide the scale of reliability one needs to account for a certain kind of context sensitivity that attaches to ability statements. That is why we need to think of abilities in terms of a modal success rate. There has to be, not one world, but a sufficient proportion of $\phi$-ing cases among the set of cases that matter.

Where possibilism gets things exactly right, though, is with respect to the first element: the restriction of the possible worlds, or situations, to the relevant ones. As we know, abilities are always had in relation to certain facts, and which facts matter will be a matter of context. This element of possibilism should be retained in a comprehensive view of abilities and is therefore part of the success view as well.

Looking back at Lewis's solution to the grandfather paradox, it is easy to see that it is the restriction to worlds that does the work in Lewis's argument. Tim can kill grandfather in relation to one set of facts, but not another. He can kill him in view of his amount of shooting training, the fact that he holds a gun to grandfather's face, and so on. But he cannot in view of the fact that grandfather lived on, in view of the fact that grandfather later fathered Tim's father, and so on.

Of course, this is then spelled out in terms of the wrong framework. According to Lewis, Tim can kill grandfather in view of him holding a gun to his face, because his killing grandfather is compossible with Tim holding a gun to his face. And Tim cannot kill grandfather in view of the fact that grandfather

1 But see Vranas (2009) for criticism of this response. 
lived on, because his killing grandfather is not compossible with grandfather living on. But compossibility is not essential to the argument. The kind of quantification that is applied to the relevant worlds is only secondary here. What really does the work is the restriction to the relevant worlds.

And because this element is retained in the success view, the success view allows for the same take on the grandfather paradox. Tim can kill grandfather relative to the fact that he holds a gun to his face, because he kills him in a sufficient proportion of cases in which he intends to kill him and holds a gun to his face. And he cannot kill him relative to the fact that grandfather lived on, because he does not kill him in a sufficient proportion of cases in which he intends to kill him and grandfather lives on.

What this shows is that Lewis's solution to the grandfather paradox stands, despite the wrong account of abilities it was originally built upon. And the way this was shown is by applying some of the main findings of this book to the line of reasoning that has led to Lewis's solution and refine it accordingly.

\subsection{Alternate possibilities contextualism about freedom}

Let me now sketch a second way in which the success view of ability can be put to work. As I will argue in what follows, it offers a fresh, albeit idiosyncratic perspective on the free will problem by allowing for a contextualist solution to it; one according to which the truth conditions of freedom ascriptions vary across contexts of utterance.

For centuries philosophers have been arguing back and forth about free will. Incompatibilists appeal to the strong intuition that nothing counts as a free action if it has been brought about via a deterministic causal chain which does not ultimately go back to the agent. Compatibilists emphasize a much more moderate conception of what it is for an action to be free - on their view, freedom is very well compatible with determinism. Both competing sides claim that their conception of free will meets the commonsensical, or at least the one and only relevant understanding of that notion; each side insists on capturing just the right kind of intuitions about freedom of the will in their account.

Which moral should be drawn? It has been argued that the debate has reached an impasse (van Inwagen 2000) or that our ordinary concept of freedom is incoherent (Double 1991; Jackson 1998). Recently, John Hawthorne (2001) has made a more constructive suggestion: freedom statements, statements in which freedom of the will is ascribed to or denied of some subject, might be context 
sensitive in the sense that they have different truth conditions across different contexts of use. ${ }^{2}$

Concerning the conflict between the compatibilist and the incompatibilist, this suggests that freedom statements have different truth conditions across ordinary contexts and contexts in which determinism comes into focus. And while the ordinary truth conditions for freedom ascriptions are often easily met, they are too demanding to be met in contexts in which we focus on determinism. This allows for a moderate compatibilism, since the truth of determinism does not inflict the truth of our ordinary freedom ascriptions. Let's dub this view "freedom contextualism". 3

If freedom contextualism is on the right track, then any account which ignores the context sensitivity of freedom statements inevitably falls short of accounting for a pertinent class of intuitions about freedom. If successful, the view therefore explains the dead-end situation between compatibilists and incompatibilists and offers a semantics of freedom statements which does justice to the most pertinent intuitions in favor of each of the competing views. In doing so, freedom contextualism provides a completely new perspective on one of the knottiest imbroglios philosophy has to offer. ${ }^{4}$

Unfortunately, the view does not seem particularly compelling as Hawthorne presents it. ${ }^{5}$ Let's look at the view. According to Hawthorne's proposal,

REA. S does x freely only if S's action is free from causal explainers beyond S's control Psst! - except for those explainers that we are properly ignoring. (ibid.)

Let's call this view "the relevant explainers account”. A causal explainer, according to Hawthorne, is "simply a state of affairs which provides an adequate causal explanation of an action" (ibid.). The truth of a freedom statement is then construed as depending on both the "causal influences upon action" and "the context of attention" (ibid.). This yields the desired freedom contextualist solution to the compatibility problem of freedom and determinism, because

[w] hen ordinary speaker utter English claims of the form 'S did x freely' (and their synonyms), they frequently speak the truth. When we approach a God's eye perspective on the causal nexus, we become ever bolder when claiming that $\mathrm{S}$ does $\mathrm{x}$ freely - for as we approach that perspective, the causes that we are properly ignoring diminishes. In the con-

2 Contextualism is very influential in epistemology. See for instance DeRose (2009).

3 Freedom contextualism has also been suggested by Rieber (2006). I'll focus on Hawthorne's version of the view in what follows.

4 But see Schulte (2014) for an interesting objection to freedom contextualism.

5 Note that Hawthorne only toys with the view. 
text of ordinary life, by contrast, the causes that are properly ignored are much greater in number and thus it is much easier for ordinary freedom ascriptions to be true. (ibid.: 69)

Hawthorne's presentation of REA remains pretty much in the abstract. He does not give examples for types of causal explainers we may properly ignore in ordinary life, but not in the face of the consideration of determinism. One natural way to flesh out what he may have in mind is this, though: in many ordinary contexts, we may ignore all but those causal explainers that are internal to the agent; all we need to care about are the agent's motivational states, for instance. Freedom ascriptions made in contexts of that kind are true because the motivational states themselves are within the agent's control.

In contexts in which determinism is considered, in contrast, we also have to take the innumerable causal explainers prior to the agent's willing into account. Hence, the condition stated in REA fails to be met in such contexts: the state of the world at some time before the agent's birth together with the laws of nature, say, is not in the agent's control. Hence, our freedom ascriptions turn out false in the face of determinism.

So much for Hawthorne's line of argument. Unfortunately, it is not very convincing. There are many problems, of which I want to highlight just one. ${ }^{6}$ REA works with the notion of control. But in doing so, it obviously begs the question against the incompatibilist. Incompatibilists will typically reject the idea that we have control over any of our motivational states (or in fact about anything whatsoever), if these motivational states (or whatever other causal explainer we are focusing on) are in turn determined by events over which we lack any kind of control. In fact, this is but one way of phrasing what the compatibilism debate is about. As Peter Schulte rightly points out,

[t]he term "control" is (...) vague and ambiguous. We speak of people controlling their movements or their facial expression, but we also say that the autonomic nervous system controls respiration, or that a thermostat controls the room temperature. It is clear, therefore, that in some ordinary sense of "control", determined agents can exercise control over their actions, but there is presumably also an ordinary sense of this term in which control and determinism are incompatible. (Schulte 2014: 673)

REA fails to factor this dimension of the debate in; it simply presupposes that the compatibilist gets the matter about control right. This is a very serious problem. In presupposing that compatibilism wins over incompatibilism from the outset,

6 I point out a variety of further problems in Jaster (forthcoming). 
REA undermines its own motivation - it makes a contextualist framework superfluous as a solution for the compatibilism issue.

Is Freedom Contextualism a nonstarter, then? Let's not give up too soon. Here is a more plausible freedom contextualist analysis:

PAP. S does $\mathrm{x}$ freely only if $\mathrm{S}$ can act otherwise than $\mathrm{x}$.

But wait, you may think. How is this a contextualist analysis of freedom statements? Isn't this just a version of the well-known principle of alternate possibilities? ${ }^{7}$ Correct. PAP is nothing other than that. What makes this a contextualist analysis is the insight that ability statements quite generally, and thus statements of the form "S can do otherwise" are in fact context sensitive. Let me explain.

The condition on freedom formulated in PAP crucially contains an ability ascription: "S can do otherwise". Since acting otherwise will by definition be an action, the ability that is ascribed is an agentive ability. Now let's plug in what we know about ability statements: they are context sensitive. According to the simplified version of the success view of agentive abilities,

SUCCESS $_{\mathrm{AA}}$. an agent has an agentive ability to $\phi$ if and only if the agent $\phi$ 's in a sufficient proportion of the relevant possible situations in which the agent intends to $\phi$, where it varies extensively across ascriber contexts which situations are relevant. $^{8}$

We are now in a position to formulate our freedom contextualist analysis more explicitly. For we can now draw on PAP and the success view to formulate the new view that PAP, rightly understood, translates into what I will call Alternate Possibilities Contextualism, or APC, for short:

APC. S does $\mathrm{x}$ freely only if $\mathrm{S}$ does something other than $\mathrm{x}$ in a sufficient proportion of the relevant possible situations in which $\mathrm{S}$ intends to do something other than $\mathrm{x}$, where it will vary across contexts which situations are relevant. ${ }^{9}$

7 Originally, the principle was formulated in terms of responsibility instead of freedom (Frankfurt 1969) and in past tense ("could have done otherwise").

8 This is a simplification in so far as it neglects that the action type that the agent intends to perform need not be (de re or de dicto) identical to $\phi$-ing, as long as $\phi$-ing vis-à-vis that intention counts as a success $(\rightarrow 4.8)$.

9 Note again that "intending to do something other than $\mathrm{x}$ " can be given the de dicto or de re reading here. 
APC has obvious merits. On the one hand, it derives the context sensitivity of "free" from an independently motivated paradigm about freedom: freedom requires alternate possibilities. ${ }^{10}$ On the other hand, it is based on the success view of ability, which is motivated independently, in virtue of its merits as a view of abilities quite generally. It is hard to think of ways in which a freedom contextualist analysis could be better motivated than that.

Note as well that, in contrast to Hawthorne's REA, APC does not beg the question against the incompatibilist. Quite the contrary. The problem about the compatibility of freedom and determinism is traditionally taken to arise primarily against the background of PAP (van Inwagen 1983, ch. 1). PAP is therefore one of the crucial premises in the incompatibilist's line of reasoning. APC starts off from this very premise. It is therefore fully in line with the incompatibilist's set of initial assumptions.

How does APC solve the puzzle about free will? The puzzle about free will, recall, is that we are inclined to ascribe freedom on a regular basis. But once determinism comes into focus, our entitlement to such ascriptions is jeopardized. On the general freedom contextualist account, the puzzle can be resolved once we notice that our ordinary claims to "freedom" and our denials of "freedom" in the face of determinism need not be contradictory. On the APC framework, that variance in truth conditions of freedom claims traces back to a variance in truth conditions of the underlying "S can act otherwise" statements. So, let's see whether the truth conditions of "can" statements vary in the right way to explain the postulated variances in our statements about freedom. What needs to be shown is that the modal base of an "S can act otherwise" statement is different when determinism is considered than in ordinary contexts.

This seems indeed plausible. When determinism is in focus, the totality of all actual facts up to the moment in which the action is performed (including facts about the natural laws) determine the modal base. In other words, the modal base will comprise only situations in which the totality of facts is preserved. In contexts of this kind, "S can act otherwise" statements turn out false. No one can perform any action in view of the fact that she is determined not to perform it. If the modal base comprises only situations in which the totality of facts up to the moment of the action is preserved, then it does not comprise any in which the agent intends to act otherwise or acts otherwise. In fact, the modal base contains only the actual situation itself in that case.

10 Of course, the principle is not uncontroversial. See Widerker \& McKenna (2003) for important contributions to the controversy. 
In ordinary contexts, this is very different. It will not be required that the totality of the actual facts be preserved in that world or that some prior state of the world and the laws necessitate some act. That is just what makes the context ordinary, as opposed to one in which determinism is considered. Which facts do go into the modal base in ordinary contexts? - That depends. Ordinary contexts have but one thing in common: determinism is not considered. And as we know from the consideration of various ordinary context ascriptions of abilities throughout the previous chapters of this book, there is not one specific set of facts that is relevant in all ordinary contexts. Sometimes, we are interested in what someone can do in view of the program in her brain, sometimes, in view of her broken limb, sometimes, in view of her dizziness, hoarseness, phobia, and so forth.

If this is true then the truth conditions of "S can act otherwise" statements will vary across ordinary contexts to the very same extent that they vary across ordinary contexts on the one hand and contexts in which determinism is considered on the other. That is not problematic, though. As long as "S can act otherwise" statements often turn out true in ordinary contexts, we can solve the puzzle about freedom just fine. And they will often come out true! In view of my muscular constitution, I can act otherwise than shying away from the spider, say, even though I cannot act otherwise in view of my phobia. The success view accounts for both. I act otherwise than shying away from the spider in a sufficient proportion of the relevant possible intention situations in which my muscular constitution is held fixed (and my phobia varied), but it is not the case that I act otherwise in a sufficient proportion of the relevant possible intention situations in which the phobia is held fixed. ${ }^{11}$

Let me wrap up. I argued that Hawthorne's freedom contextualism is not particularly appealing, because it begs the question against incompatibilists about freedom. I then proposed a different freedom contextualist view. Alternate Possibilities Contextualism (APC) starts off from a version of the Principle of Alternate Possibilities and combines that principle with the success view of ability. For an agent to be free, I argued, it has to be true that the agent acts otherwise in a sufficient proportion of the relevant possible situations in which the agent intends to act otherwise, where it will vary by context which situations are relevant. The view is well-motivated, does not beg the question against the incompatibilist, and explains the context-shifts posited by the freedom contextualist.

11 In Jaster (forthcoming), I argue that the truth values of freedom ascriptions vary in accordance to these variances in "S can act otherwise" statements. If this is true, then the truth conditions of freedom statements vary across ordinary contexts to the same amount as they vary across ordinary contexts and contexts in which determinism is considered. 
We can conclude that freedom contextualism, if plausible at all, is quite plausibly spelled out in terms of APC.

The question, of course, is how plausible freedom contextualism as whole turns out to be. Among other things, the answer to this question hinges crucially on whether or not a contextualist semantics of freedom ascriptions can be bolstered on the basis of our ordinary practice of freedom ascriptions. ${ }^{12}$ I have not addressed that question and I wish to remain neutral on it. ${ }^{13}$ My main purpose here was to show how the success view of ability can be put to work when it comes to actual philosophical problems. And as I hope to have shown, the view provides an interesting toolbox, which allows for a fresh assessment of some well-established problems.

12 Epistemic contextualists have gone to great lengths to establish such ordinary language evidence for contextualism about knowledge. See for instance DeRose (2005).

13 But see again Jaster (forthcoming) for a discussion. 